\title{
Viabilidade de incorporação de resíduo de scheelita em argamassa
}

Com o objetivo de conciliar o progresso do setor construtivo com a preservação do meio ambiente, têm-se desenvolvido estudos a fim de minimizar os impactos ambientais causados pela indústria da construção. Assim, o estudo da produção de materiais alternativos constitui-se em uma vertente promissora nesse sentido. Entre os materiais cujas pesquisas têm sido desenvolvidas, encontra-se a argamassa, material amplamente utilizado durante processo construtivo, sendo composto, de forma geral, por aglomerante, agregado miúdo e água. Diante disso, o presente trabalho teve como objetivo seguir a linha de pensamento supracitada, produzindo argamassa alternativa incorporada com resíduo de scheelita, em substituição parcial ao agregado miúdo natural, verificando o seu desempenho através da análise da resistência à compressão simples e da absorção de água. Para tanto, realizou-se a caracterização física dos materiais e em seguida, a dosagem e moldagem dos corpos de prova. Foram moldados 5 corpos de prova para cada composição do traço 1:3 (em volume) e para cada idade de cura (7, 14 e 28 dias). Após a cura dos corpos de prova, realizou-se o ensaio de resistência à compressão simples e absorção de água, para a análise do desempenho da argamassa alternativa. Verificou-se que aos 28 dias as duas composições estudadas (30\% e 50\%) apresentaram resistências próximas à argamassa de referência e valores de absorção de água um pouco superiores que a mesma. Diante dos resultados obtidos, concluiu-se que há viabilidade de incorporação do resíduo de scheelita na argamassa, o que reflete em uma promissora contribuição para a indústria da construção, dos materiais e para a preservação do meio ambiente.

Palavras-chave: Resíduo de scheelita; Argamassa alternativa; Materiais alternativos.

\section{Viability of incorporating scheelite waste into mortar}

In order to reconcile the progress of the construction sector with the preservation of the environment, studies have been developed in order to minimize the environmental impacts caused by the construction industry. Thus, the study of the production of alternative materials is a promising aspect in this sense. Among the materials whose researches have been developed, is the mortar, a material widely used during the construction process, being composed, in general, by agglomerant, small aggregate and water. In view of this, the present work aimed to follow the above mentioned line of thought, producing alternative mortar incorporated with scheelite waste, in partial substitution of the natural small aggregate, verifying its performance through the analysis of simple compression resistance and water absorption. For this, the physical characterization of the materials was carried out and then the dosage and moulding of the specimens. Five specimens were molded for each composition of 1:3 trace (in volume) and for each age of cure (7,14 and 28 days). After curing the specimens, the test of resistance to simple compression and water absorption was performed, for the analysis of the performance of the alternative mortar. It was verified that at 28 days the two compositions studied $(30 \%$ and $50 \%$ ) presented resistance close to the reference mortar and water absorption values a little higher than the same. Given the results obtained, it was concluded that there is feasibility of incorporating scheelite waste in the mortar, which reflects in a promising contribution to the construction industry, materials and environmental preservation.

Keywords: Scheelite waste; Alternative mortar; Alternative materials.

Topic: Engenharia de Materiais

Reviewed anonymously in the process of blind peer
Received: 06/03/2021

Approved: 22/03/2021
Raquel Ferreira do Nascimento (iD)

Universidade Federal do Rio Grande do Norte, Brasil http://lattes.cnpq.br/6299630411846009

http://orcid.org/0000-0001-5376-9364

raquelfn96@hotmail.com

Suelen Silva Figueiredo Andrade

Universidade Federal de Campina Grande, Brasil

http://lattes.cnpq.br/6976651417711520

suelensfigueiredo@gmail.com

Leonardo de Souza Dias (iD

Universidade Federal do Rio Grande do Norte, Brasil http://lattes.cnpq.br/5525115500936540 http://orcid.org/0000-0001-5925-2171 leonardodiaspb@gmail.com

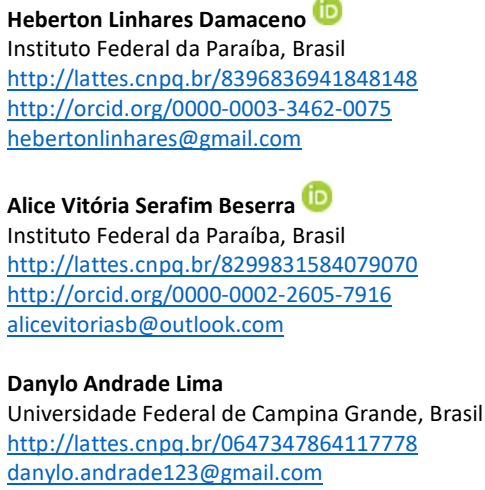

Danylo Andrade Lima

Universidade Federal de Campina Grande, Brasil http://lattes.cnpq.br/0647347864117778

danylo.andrade123@gmail.com

\begin{abstract}
Diego Paiva Bezerra
Universidade Estadual da Paraíba, Brasil

http://lattes.cnpq.br/3610261129908017

diegop.bezerra@hotmail.com

Cinthia Maria Abreu Claudino (iD

Universidade Estadual da Paraíba, Brasil http://lattes.cnpq.br/97222533812780740 http://orcid.org/0000-0003-4233-6082

cinthiamariaac@gmail.com

José Lucas Pessoa de Oliveira (iD)

Instituto Federal da Paraíba, Brasil

http://lattes.cnpq.br/6709461469265977

http://orcid.org/0000-0002-6546-1380

lucaspessoa.engcivil@gmail.com
\end{abstract}

Referencing this:

NASCIMENTO, R. F.; ANDRADE, S. S. F.; DIAS, L. S.; DAMACENO, H. L.; BESERRA, A. V. S.; LIMA, D. A.; BEZERRA, D. P.; CLAUDINO, C. M. A.; OLIVEIRA, J. L. P.. Viabilidade de incorporação de resíduo de scheelita em argamassa. Revista Ibero Americana de Ciências Ambientais, v.12, n.3, p.431-439, 2021. DOI: http://doi.org/10.6008/CBPC2179$\underline{6858.2021 .003 .0035}$ 


\section{INTRODUÇÃO}

Cerca de $20 \%$ a $50 \%$ de recursos naturais são consumidos pela cadeia produtiva da construção civil. As atividades construtivas necessitam de uma considerável quantidade de materiais inertes, tais como areia e cascalho, que usualmente são fornecidos por meio da extração de sedimentos aluviais. A extração dos mesmos modifica o perfil dos rios e o seu equilíbrio, além de introduzir problemas ambientais como modificação em sua estrutura hidrológica e hidro geológica (BRASILEIRO et al., 2015).

Por essa razão, faz-se necessário conciliar a construção civil com a preservação do meio ambiente, de maneira tal, que a humanidade não sofra as possíveis consequências decorrentes da negligência para com o mesmo. É necessário, então, aliar-se ao conceito de desenvolvimento sustentável, permitindo o equilíbrio entre o progresso econômico e a preservação da natureza, de forma que, seja possível para gerações futuras, desfrutarem do meio sem maiores consequências (SANTANA JÚNIOR, 2016).

Nesse cenário, surgem os materiais de construção alternativos, que segundo Brosler (2011) são aqueles confeccionados utilizando recursos que podem advir do meio natural, bem como da reutilização de produtos recicláveis ou de objetos que possuíam outra função antes de se tornar parte constituinte de uma construção. Barroca (2013) afirma que a forma mais eficiente para a indústria da construção se tornar uma atividade sustentável passa pela incorporação de resíduos de outras indústrias em materiais de construção. De fato, essa é uma alternativa para que haja conciliação entre os dois ramos.

Diante disso, e com o desenvolvimento de novas técnicas, é possível realizar a incorporação de resíduos produzidos por indústrias, como a indústria da mineração na fabricação de tais materiais, possibilitando que elementos a princípio sem utilidade, desempenhe um importante papel na composição de novos produtos, contribuindo ainda, com a minoração dos impactos provocados pelos dois setores da economia, já destacados.

O uso de resíduos derivados da mineração tem se mostrado de muita importância nos materiais que possuem matrizes cimentícias, como a argamassa, tanto nas propriedades do estado fresco quanto do endurecido e também no aspecto da durabilidade. A incorporação de resíduos na produção de tais materiais pode acarretar numa maior economia de energia, além de contribuir para o desenvolvimento sustentável (SANTOS, 2008).

Assim, o objetivo do presente estudo é avaliar o desempenho mecânico e a absorção de água de argamassas produzidas com incorporação do resíduo originado do beneficiamento da scheelita (material pertencente à classe dos tungstatos), em substituição parcial ao agregado miúdo da mistura, a fim de verificar a viabilidade de redução de utilização da areia (recurso não renovável), bem como propor uma nova destinação eficaz ao resíduo da mineração.

\section{MATERIAIS E MÉTODOS}

Foi utilizada areia lavada média, comumente utilizada nas construções locais, proveniente do município de São Domingos-PB. O aglomerante usado foi o cimento Portland CP II Z 32, por ser o mais comum 
na região. O resíduo da mineração empregado foi o resíduo de scheelita, proveniente do município de Currais Novos - RN. Para mistura, utilizou-se a água da rede de abastecimento do município.

\section{Coleta e beneficiamento das matérias primas}

O agregado natural foi adquirido através da compra do produto comercializado no município de Pombal-PB, sendo proveniente do município de São Domingos - PB. O aglomerante foi obtido pela compra do mesmo em loja de materiais de construção. A coleta do resíduo, foi realizada no município de Currais Novos - RN, na mina presente na região

Foi realizado o beneficiamento dos agregados miúdos (areia e resíduo) mediante peneiramento dos mesmos na peneira de malha $2,4 \mathrm{~mm}$, sendo utilizado na produção da argamassa, a porcentagem passante nesta peneira.

\section{Análise granulométrica}

A análise granulométrica consiste em determinar a quantidade de cada fração de grãos presente no material, a fim de conhecer as dimensões de suas partículas, visto que estas têm grande influência no resultado do produto final. $O$ procedimento foi realizado em conformidade com a ABNT NM 248/03.

\section{Massa unitária, massa específica e finura}

A determinação da massa unitária dos materiais foi realizada segundo a NBR NM 45 (ABNT, 2006). A massa específica da areia e do resíduo foi obtida segundo a ME 084 (DNER, 1995) e a do cimento baseou-se na NBR 16605 (ABNT, 2017). A finura do cimento foi determinada de acordo com a NBR 11579 (ABNT, 2013).

\section{Moldagem e cura dos corpos de prova}

Os corpos de prova foram moldados conforme previsto pela norma NBR 7215 (ABNT, 1997), utilizando-se moldes cilíndricos com dimensões de $5 \mathrm{~cm}$ de diâmetro e $10 \mathrm{~cm}$ de altura. $O$ traço usado foi 1:3 - em volume (comumente empregado em obras), sendo feitos corpos de prova de referência e com incorporação de resíduo nas proporções de 30\% e 50\% da massa da areia. Foram moldados 5 corpos de prova para cada composição de cada traço e para cada idade de cura. Foi realizada a cura submersa dos corpos de prova nas idades de 7, 14 e 28 dias.

\section{Resistência à compressão simples}

Para a determinação da resistência à compressão simples, os corpos de prova foram rompidos em prensa hidráulica manual SKAY de acordo com a NBR 7215 (ABNT, 1997). A NBR 13281 (ABNT, 2005) estabelece as classes de resistência apresentadas na Tabela 1, a depender dos valores obtidos. 
Tabela 1: Resistência à compressão (ABNT NBR 13279/05).

\begin{tabular}{ll}
\hline Classe & Resistência à compressão $(\mathrm{MPa})$ \\
\hline P1 & $\leq 2,0$ \\
\hline P2 & 1,5 a 3,0 \\
\hline P3 & 2,5 a 4,5 \\
\hline P4 & 4,0 a 6,5 \\
\hline P5 & 5,5 a 9,0 \\
\hline P6 & $>8$
\end{tabular}

\section{Absorção de água}

A determinação da absorção de água foi realizada conforme a metodologia recomendada pela NBR 9778 (ABNT, 2009).

Os valores individuais de absorção de água (A), expressos em porcentagem (\%), foram obtidos pela Equação 1, enquanto que a absorção média foi determinada pela média aritmética de cinco repetições.

$$
A=[(\mathrm{M} 2-\mathrm{M} 1) / \mathrm{M} 1]^{*} 100 \text { Equação (1) }
$$

\section{RESULTADOS E DISCUSSÃO}

\section{Granulometria}

Após a coleta e aquisição dos materiais, realizou-se a análise granulométrica do resíduo e do agregado natural, a fim de identificar o tamanho dos grãos que os compõe. A Figura 1 apresenta as curvas granulométricas da scheelita e da areia.

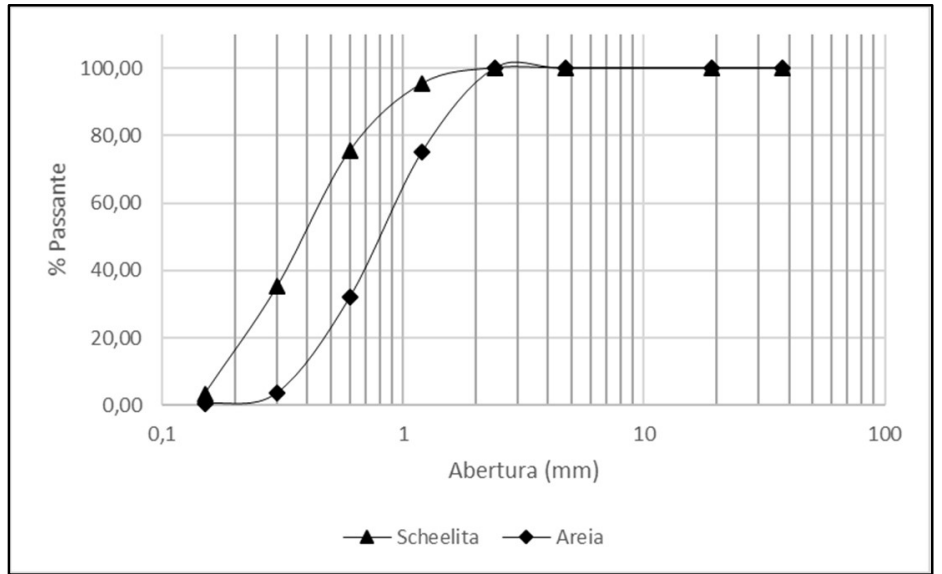

Figura 1: Curvas granulométrica da scheelita e da areia.

A maior porcentagem retida do resíduo de scheelita encontra-se nas malhas de 0,30 $\mathrm{mm}$ e 0,15 $\mathrm{mm}$, representando $71,97 \%$ do total. Isso revela que o resíduo apresenta grande quantidade de partículas finas. Além disso, possui maior porcentagem passante na peneira com abertura $0,15 \mathrm{~mm}(3,43 \%)$ se comparada com a areia (0,40\%). Esse fato pode levar ao aumento de absorção de água por parte da partícula do material, em razão do aumento da área superficial e interferir, ainda que em pequeno nível, na resistência final do produto, a depender a proporção de incorporação na argamassa. 
Para o presente trabalho foram utilizados os grãos de areia e resíduos partir de 1,2 mm, englobando todas as outras frações abaixo desse valor, a fim de proporcionar maior trabalhabilidade à argamassa desenvolvida.

\section{Massa unitária, massa especifica e módulo de finura}

Os resultados referentes à massa unitária, massa específica e finura dos materiais são apresentados na Tabela 2.

Tabela 2: Características físicas dos materiais.

\begin{tabular}{llllll}
\hline Material & Massa Unitária $\left(\mathbf{g} / \mathbf{c m}^{\mathbf{3}}\right)$ & Massa específica $\left(\mathbf{g} / \mathbf{c m}^{\mathbf{3}}\right)$ & Módulo de Finura & Finura (\%) & $\begin{array}{l}\text { Diâmetro } \\
\text { Máximo (mm) }\end{array}$ \\
\hline Areia & 1,53 & 2,60 & 2,89 & - & 2,40 \\
\hline Resíduo de scheelita & 1,56 & 2,68 & 1,90 & - & 2,40 \\
\hline Cimento & 1,40 & 2,96 & - & 2,7 & - \\
\hline
\end{tabular}

As massas unitária e específica do rejeito de scheelita são maiores que as da areia, fato já esperado em razão do resíduo conter porções, ainda que pequenas de tungstênio, sendo este um mineral não metálico com densidade elevada na ordem de $19,35 \mathrm{~kg} / \mathrm{dm}^{3}$ (ALVES et al., 2016). A massa específica da scheelita é cerca de 3,07\% maior que a do agregado natural, o que resultará em um produto final mais pesado.

A massa específica do agregado é diretamente proporcional ao teor de finos que possui. Assim, a massa especifica maior da scheelita em relação a areia é o indicativo da maior quantidade de partículas finas no rejeito, fato comprovado pelo ensaio de granulometria.

A scheelita apresenta módulo de finura menor em relação a areia, tendo em vista a grande quantidade de partículas retida nas malhas de 0,30 $\mathrm{mm}$ e 0,15 $\mathrm{mm}$, fato este que pode contribuir para o preenchimento de vazios que os grãos do agregado natural não são capazes de preencher, mas podem, por outro lado, aumentar a quantidade necessária de água na mistura, em razão da maior área superficial.

\section{Dosagem}

As relações água/cimento para cada composição são apresentadas na Tabela 3. É possível perceber que há uma relação direta entre o aumento da quantidade de resíduo incorporado e a elevação da relação água/cimento. Isso ocorre devido a maior quantidade de finos presentes na scheelita que reflete em maior trabalhabilidade, porém, implica também em partículas com maiores superfícies específicas em relação ao agregado natural e um consequente aumento da absorção de água pelo material. Assim, com o aumento da proporção de resíduo na argamassa, a quantidade da água de amassamento requerida na mistura também aumentou.

Tabela 3: Relações água/cimento.

\begin{tabular}{ll}
\hline Proporção de resíduo (\%) & Relação a/c \\
\hline $\mathbf{0} \%$ & 0,65 \\
\hline $\mathbf{3 0}$ & 0,70 \\
\hline $\mathbf{5 0 \%}$ & 0,75 \\
\hline
\end{tabular}




\section{Resistência à compressão}

A Tabela 4 e a Figura 2 apresentam os resultados do ensaio de resistência a compressão para todas as proporções e idades de cura avaliadas e os respectivos desvios padrões.

Tabela 4: Resultados do ensaio de resistência à compressão.

\begin{tabular}{llll}
\hline Resistência à compressão (MPA) - Traço 1:3 (em volume) & & \\
\hline Cura/proporção & $\mathbf{0 \%}$ & $\mathbf{3 0 \%}$ & $\mathbf{5 0 \%}$ \\
\hline $\mathbf{7}$ dias & $7,79 \pm 1,8$ & $10,5 \pm 0,48$ & $9,61 \pm 0,99$ \\
\hline $\mathbf{1 4}$ dias & $10,47 \pm 2,53$ & $10,95 \pm 0,98$ & $10,00 \pm 0,50$ \\
\hline $\mathbf{2 8}$ dias & $11,01 \pm 2,47$ & $11,27 \pm 1,78$ & $10,38 \pm 0,66$
\end{tabular}

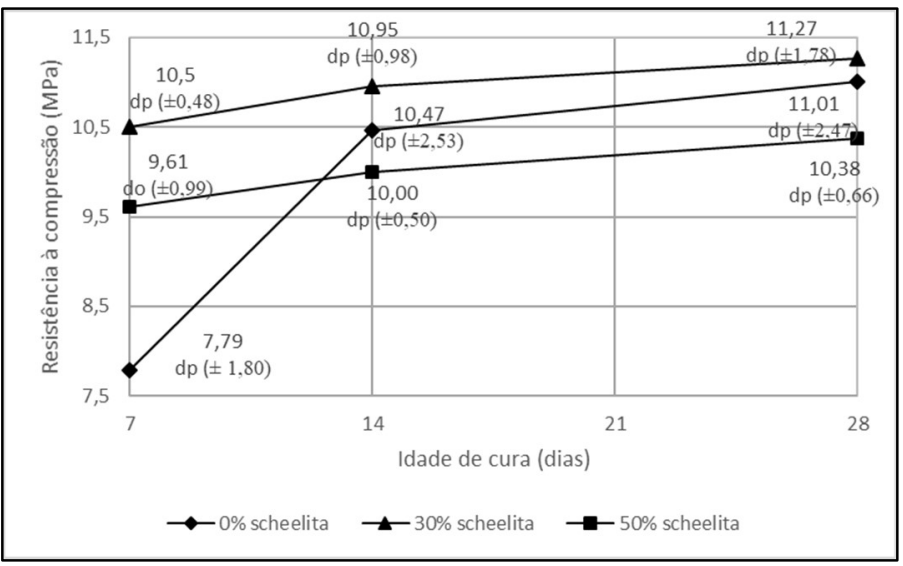

Figura 2: Resistência à compressão.

Ao analisar os dados referentes à resistência à compressão, é possível perceber que as argamassas com composições de $30 \%$ e $50 \%$ de resíduo de scheelita obtiveram resultados satisfatórios, maiores que o mínimo estabelecido pela NBR 13279 (ABNT, 2005), a partir dos 7 dias de cura. Valores semelhantes e inferiores de resistência foram observados por um autor em 2016, para os traços em volume 1:1:6 (cimento:cal:areia) e 1:3 (cimento: areia) incorporados com rejeito de scheelita.

Aos 7 dias, as duas composições de scheelita para o traço 1:3 apresentam resistências maiores que a argamassa sem nenhuma substituição de resíduo, ocorrendo o mesmo para a composição de $30 \%$ aos 14 e 28 dias. A composição de 50\% nas duas últimas idades de cura não apresentou valores superiores de resistência à composição com $0 \%$ de resíduo, mas atingiu valores bem próximos, com diferenças de 0,47 e 0,63 MPa para 14 e 28 dias, respectivamente.

As maiores resistências iniciais (7 dias) para as argamassas incorporadas com resíduo se devem ao fato de suas partículas, mais finas que as da areia, se acomodarem mais facilmente logo no início do processo de cura. Porém nota-se que à medida que se passa o tempo (14 e 28 dias) os grãos de areia passam a se acomodar de forma mais eficaz, resultando em maiores resistências, ainda que com pequenas diferenças, quando comparadas as demais composições.

A argamassa com proporção de 50\% de resíduo, apesar de ter maior resistência inicial que a argamassa de referência, não obteve valores maiores no final (apesar de bem próximos as demais composições), revelando que uma argamassa produzida com tal proporção de scheelita em substituição ao agregado natural, não apresenta melhorias, mas mantém basicamente o mesmo comportamento que o 
material feito apenas com areia. É possível perceber, entretanto, que para uma proporção de $30 \%$ de resíduo, a resistência aumenta, ainda que em pequenas proporções, em relação a argamassa de referência. Assim, essa proporção de scheelita proporcionou melhorias mecânicas ao material.

Em suma, pode-se afirmar que em razão das pequenas diferenças das resistências de ambas composições ( $30 \%$ e $50 \%$ ) em relação a argamassa de referência ( $0 \%$ de resíduo), e levando em consideração ainda o desvio padrão das mesmas, o desempenho mecânico das argamassas com incorporação do resíduo praticamente não se alterou, mantendo a qualidade do produto final.

Dessa forma, nota-se que apesar de possuir mais partículas finas em relação a areia e mesmo sendo necessário, na maioria das composições, incorporar mais água de amassamento na mistura, devido à maior superfície específica dos grãos, não houve interferência significativa nos valores finais das resistências.

Além disso, as relações a/c já apresentadas na Tabela 3 demonstram que houve pouca variação em relação à quantidade de água acrescentada ao comparar com o material original. Devido à pequena diferença, as resistências não apresentaram variações significativas aos 28 dias. 0 acréscimo na resistência entre 7 e 28 dias foi de 7,33\% para a composição de $30 \%$ e 8,01\% para a de $50 \%$.

De acordo com a Tabela 1, que apresenta as classes de nomenclatura para as argamassas segundo a NBR 13281 (ABNT, 2005) pode-se, pelos resultados obtidos de resistência, classificar as argamassas com incorporação de scheelita para 28 dias, de forma resumida na Tabela 5.

Tabela 2: Classificação e nomenclatura das argamassas.

\begin{tabular}{ll}
\hline Proporção de resíduo (\%) & Nomenclatura \\
\hline $\mathbf{0} \%$ & $\mathrm{P} 6$ \\
\hline $\mathbf{3 0 \%}$ & $\mathrm{P} 6$ \\
\hline $\mathbf{5 0 \%}$ & $\mathrm{P} 6$ \\
\hline
\end{tabular}

\section{Absorção de água}

A Tabela 6 e a Figura 3 apresentam os resultados do ensaio de absorção de água para todas as proporções e idades de cura avaliadas e os respectivos desvios padrões.

Tabela 6: Resultados do ensaio de absorção de água.

\begin{tabular}{llll}
\hline Absorção de água (\%) - Traço 1:3 (em volume) & & \\
\hline Cura/proporção & $\mathbf{0 \%}$ & $\mathbf{3 0 \%}$ & $\mathbf{5 0 \%}$ \\
\hline $\mathbf{7}$ dias & $9,60 \pm 0,30$ & $11,56 \pm 0,61$ & $11,84 \pm 0,52$ \\
\hline $\mathbf{1 4}$ dias & $9,49 \pm 0,41$ & $10,63 \pm 0,26$ & $11,36 \pm 0,47$ \\
\hline $\mathbf{2 8}$ dias & $9 \pm 0,48$ & $10,57 \pm 0,71$ & $10,89 \pm 0,24$ \\
\hline
\end{tabular}

Os resultados de absorção aos 28 dias das argamassas com incorporação do resíduo de scheelita apresentaram-se relativamente próximos aos valores da argamassa de referência. As diferenças entre os valores de absorção das argamassas com e sem resíduo é proveniente da maior quantidade de finos do rejeito (passante na peneira de $0,15 \mathrm{~mm}$ ), do que na areia. Com maior superfície específica das partículas, ocorre maior absorção de água, fato que pode ser notado ao analisar a Tabela 5, embora haja pouco aumento da relação a/c, das proporções de $0 \%$ para a de $30 \%$ e $50 \%$.

Assim, apesar da scheelita apresentar uma faixa maior de partículas entre 0,30 mm e 0,15 mm, 
fundamental no preenchimento de vazios de tal dimensão que a areia não consegue preencher por completo, a maior quantidade de água absorvida pelos finos, proporciona um valor de absorção um pouco maior.

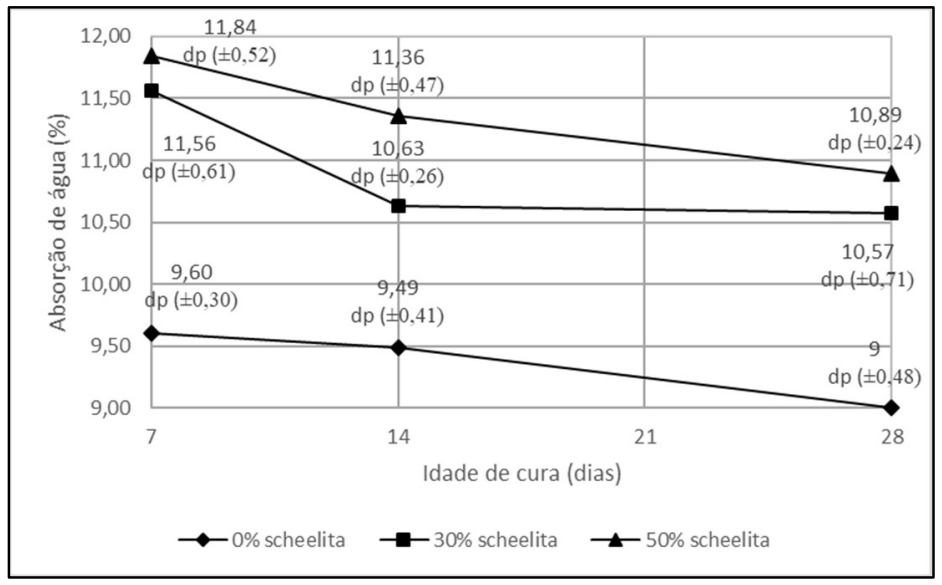

Figura 3: Absorção de água.

Ocorre decréscimo de absorção para todas as composições da primeira idade de cura para a última, fato explicado pela acomodação das partículas, redução de vazios, compactação e aquisição de resistência ao logo do processo de cura. Ocorre diminuição de 8,56\% para a argamassa de 30\% e 8,02\% para a de 50\%, entre 7 e 28 dias.

As Figuras 4 e 5 apresentam a relação entre os gráficos de absorção de água e resistência à compressão para as três idades de cura. Nota-se que há uma relação inversa entre as duas propriedades avaliadas, tendo em vista, que à medida que os dias de cura aumentam, maior é a acomodação das partículas de agregado, e, portanto, menor a quantidade de vazios na argamassa. Isso reflete em diminuição da capacidade de absorção de água por parte do material, maior compacidade e maiores resistências.

Em 2016, em um estudo, verificou-se valores de absorção maiores que os encontrados na presente pesquisa para os traços estudados de argamassa incorporada com scheelita, variando entre $13 \%$ e $15 \%$ da massa da areia. Assim, obteve também resistências inferiores às aqui apresentadas.

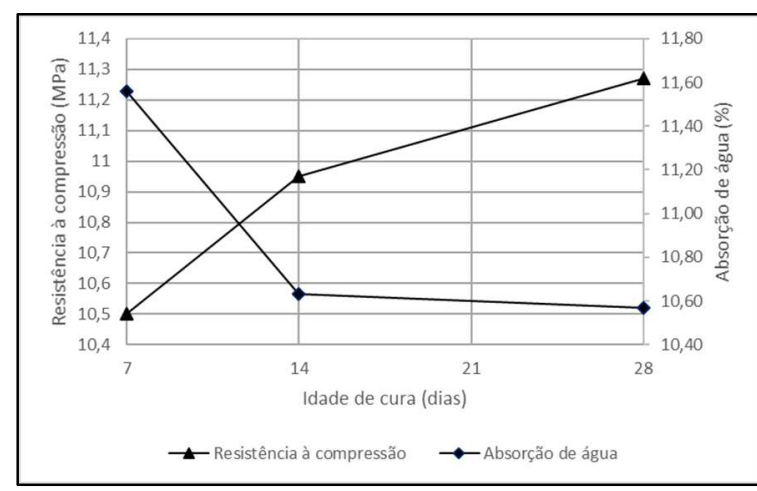

Figura 4: Absorção de água x Resistência à compressão (30\%).

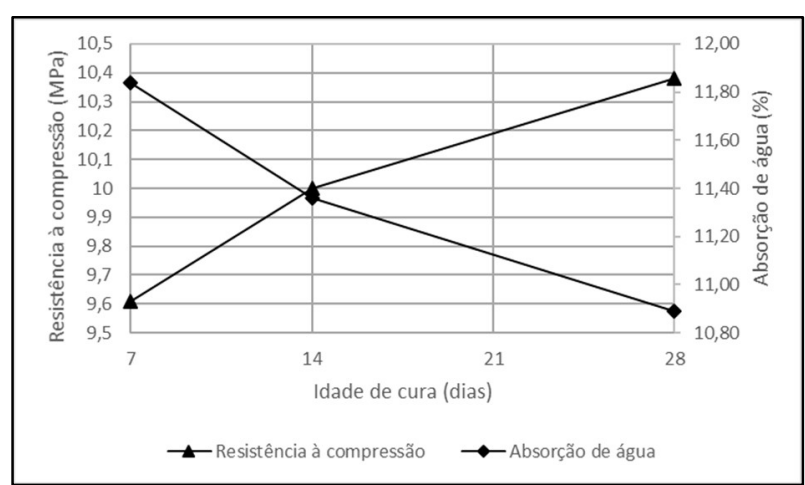

Figura 5: Absorção de água x Resistência à compressão $(50 \%)$.

\section{CONCLUSÕES}

O estudo consistiu em avaliar as propriedades de resistência à compressão e absorção de água de argamassas incorporadas com $30 \%$ e $50 \%$ de resíduo de scheelita, que substituiu parcialmente o agregado 
natural da mistura de traço 1:3 (em volume).

A partir dos resultados obtidos é possível concluir que: Há viabilidade de incorporação do resíduo de scheelita na argamassa de traço 1:3, visto que, os valores obtidos nos ensaios de resistência à compressão simples e absorção de água, utilizados para avaliar o comportamento do material, foram satisfatórios para todas as composições, desde a primeira idade de cura estudada, de acordo com as normas e a literatura utilizada como referência.

Verificou-se que as argamassas produzidas com 30\% e 50\% de resíduo obtiveram valores de resistência, aos 28 dias, bem próximos à argamassa de referência, com apenas uma pequena diferença de valores, de tal forma que a composição de $30 \%$ apresentou resistência um pouco superior a argamassa com $0 \%$ de resíduo e a de $50 \%$, um pouco inferior. Mas ao levar em consideração a pequena diferença de resistência entre as composições é possível afirmar que o resíduo não proporcionou significativa alteração no material.

As diferenças entre os valores de absorção das argamassas com e sem resíduo é proveniente da maior quantidade de finos do rejeito (passante na peneira de $0,15 \mathrm{~mm}$ ), do que na areia. Com maior superfície específica das partículas, ocorre maior absorção de água. Assim, quanto maior a proporção de resíduo maior os valores de absorção de água, apesar de os mesmos se apresentarem não muito distantes do valor de referência.

\section{REFERÊNCIAS}

ALVES, B. S.; PEREIRA, D. D.; IZÍDIO JÚNIOR, L. R.; GURGEL, M. T.. Análise comparativa do agregado miúdo com o rejeito da scheelita para aplicação na construção civil. In: CONGRESSO BRASILEIRO DE ENGENHARIA E CIÊNCIA DOS MATERIAIS, 22. Anais. Natal, 2016. p.1073-1081.

ABNT. Associação Brasileira de Normas Técnicas. NBR NM 45: Agregados - Determinação da massa unitária e do volume de vazios. Rio de Janeiro, 2006

ABNT. Associação Brasileira de Normas Técnicas. NBR NM 248: Agregados - Determinação da composição granulométrica. Rio de Janeiro, 2003.

ABNT. Associação Brasileira de Normas Técnicas. NBR 7215 : Cimento Portland - Determinação da resistência à compressão. Rio de Janeiro, 1997.

ABNT. Associação Brasileira de Normas Técnicas. NBR 11579: Cimento Portland - Determinação da finura por meio da peneira $75 \mu \mathrm{m}$ (№ 200). Rio de Janeiro, 2013.

ABNT. Associação Brasileira de Normas Técnicas. NBR 13281: Argamassas de assentamento e revestimento: requisitos. Rio de Janeiro, 2005.

ABNT. Associação Brasileira de Normas Técnicas. NBR 16605: Cimento Portland e outros materiais em pó Determinação da massa específica. Rio de Janeiro, 2017.
BARROCA, P. A. G.. Comportamento reológico e mecânico de argamassas com agregados leves. Dissertação (Mestrado em Engenharia Civil) - Universidade da Beira Interior, Covilhã, 2013.

BRASILEIRO, L. L.; MATOS, J. M. E.. Revisão bibliográfica: reutilização de resíduos da construção e demolição na indústria da construção civil. Cerâmica, v.61, n.358, p.178189, 2015. DOI: https://doi.org/10.1590/036669132015613581860

BROSLER, T. M.. Materiais não convencionais na construção civil: presente, passado e futuro no processo de conhecimento dos assentados de Mogi Mirim - SP. Dissertação (Mestrado em Engenharia Agrícola) Universidade Estadual de Campinas, Campinas, 2011.

DNER. Departamento Nacional de Estradas de Rodagem. ME 084: Agregado miúdo - determinação da densidade real. Rio de Janeiro: DNER, 1995

SANTANA JUNIOR, H.. O consumo na estratégia de desenvolvimento sustentável brasileira. Dissertação (Mestrado em Desenvolvimento, Sociedade e Cooperação Internacional) - Universidade de Brasília, Brasília, 2016.

SANTOS, M. L. L. O.. Aproveitamento de resíduos minerais na formulação de argamassas para a construção civil. Tese (Doutorado em Ciência e Engenharia de Materiais) Universidade Federal do Rio Grande do Norte, Natal, 2008.

A CBPC - Companhia Brasileira de Produção Científica (CNPJ: 11.221.422/0001-03) detém os direitos materiais desta publicação. Os direitos referem-se à publicação do trabalho em qualquer parte do mundo, incluindo os direitos às renovações, expansões e disseminações da contribuição, bem como outros direitos subsidiários. Todos os trabalhos publicados eletronicamente poderão posteriormente ser publicados em coletâneas impressas sob coordenação da Sustenere Publishing, da Companhia Brasileira de Produção Científica e seus parceiros autorizados. Os (as) autores (as) preservam os direitos autorais, mas não têm permissão para a publicação da contribuição em outro meio, impresso ou digital, em português ou em tradução. 